\title{
O desafio da ética da responsabilidade de Hans Jonas como resposta à nova era da civilização tecnológica
}

The challenge of Hans Jonas' responsibility ethics in response to the new era of technological civilization

\section{Ana Paula de Araújo Lima ${ }^{1}$}

RESUMO: O presente artigo pretende elucidar a problemática da técnica no pensamento do filósofo alemão Hans Jonas, tendo como itinerário o "princípio responsabilidade" e seus desdobramentos para se pensar uma ética que engloba uma nova era frente aos avanços tecnológicos, levando em consideração o agir humano que vem se modificando em consequência desses aparatos tecnológicos disponíveis. Para tanto exploraremos alguns pressupostos básicos do pensamento do autor que são necessários para o desenvolvimento desse trabalho, tais como: os Novos e Velhos Imperativos, o Ser e o Dever, a Heurística do Temor, a Responsabilidade Natural e a Política, elementos importantes para uma breve elucidação em relação à filosofia de Hans Jonas que desenvolveu de maneira sistemática e coerente uma teoria ética pautada em um princípio o qual denominou de "responsabilidade".

PALAVRAS-CHAVE: Hans Jonas; Teoria Ética; Tecnologia; Responsabilidade.

ABSTRACT: This article airms to elucidate the problems of technique in the thought of German philosopher Hans Jonas, whose itinerary the "responsibility principle" and its implications for thinking about ethics that includes a new forward age to technological advances, considering that human action has been changing as a result of these technological devices available. For both explore some basic assumptions of the author's thought that are necessary for the development of this work, such as: the Old e New Imperatives, Being and Duty, the Heuristics of Fear, Natural and Political Responsibility, important elements for a brief elucidation in relation to the philosophy of Hans Jonas who developed a systematic and coherent way an ethical theory grounded in a principle which called "responsibility".

KEYWORDS: Hans Jonas; Ethical Theory; Technology; Responsibility.

\footnotetext{
${ }^{1}$ Mestra em Filosofia pelo Programa de Pós-Graduação em Ética e Epistemologia, pela Universidade Federal do Piauí.paulatic@bol.com.br.
} 


\section{INTRODUÇÃO}

O presente artigo visa esclarecer a problemática da técnica no pensamento do filósofo Hans Jonas (1903-1993), tendo como diretriz a sua principal obra O princípio responsabilidade: ensaio de uma ética para uma civilização tecnológica (1979), na qual o autor aborda pressupostos importantes para se pensar uma ética voltada para a coletividade. Profundamente marcado pelo advento do terrível incidente que aconteceu em Hiroshima e Nagasaki, ou seja, as explosões das duas bombas nucleares que levaram a milhares de mortes só no ataque, sem falar nas milhares de vidas que foram afetadas ao longo dos anos devido à exposição radioativa, Hans Jonas voltou o seu pensamento para os problemas de cunho ético, principalmente aqueles que poderiam surgir a partir dos avanços tecnológicos e suas consequências, desenvolvendo uma consciência mais ampliada em relação à interferência causada por estes avanços no desenvolvimento da vida em escala planetária.

Hans Jonas é considerado um dos poucos pensadores do Ocidente que pôde acompanhar de perto os dramas profundos que aconteceram nesse período em todo o mundo. Sua vida intelectual sofreu forte influência dos filósofos Edmund Husserl e Martin Heidegger. Durante a década de 1970, preocupou-se com as questões éticas que surgiram a partir dos avanços tecnológicos e suas implicações, demonstrando grande preocupação com o futuro da humanidade, parte, então, para uma jornada intelectual enraizada no princípio ético fundamentado em uma ontologia, cuja atenção principal volta-se para a existência autêntica da vida humana na Terra.

\section{ÉTICA DA REPONSABILIDADE}

Hans Jonas propôs em seus escritos elucidar a problemática da técnica a partir de uma ética da responsabilidade para com as gerações vindouras, pois estas não devem ser responsabilizadas por desmedidas causadas por gerações presentes. Elas devem, sim, ter seus direitos garantidos e viverem em um ambiente saudável e isso só poderá ser garantido levando-se em consideração a preservação ambiental.

Para Hans Jonas nenhuma ética anterior havia pensado em um futuro distante, pois elas não refletiam sobre a relação homem x natureza por se acreditar que, até então, que a ação do homem tinha um impacto quase irrelevante em relação ao meio ambiente. Segundo o autor, imaginava-se que o "alcance efetivo da ação era pequeno, o intervalo de tempo para a previsão, definição de objetivo e imputabilidade era curto, e limitado o controle sobre as circunstâncias" (JONAS, 2006, p.35). O que leva a crer que as éticas anteriores tinham um caráter antropocêntrico, a ética tinha a ver com a relação direta entre iguais. Marcado por uma ideia bem 
diferente destas, Hans Jonas propõe uma reformulação no cenário ético e coloca a responsabilidade como fator determinante para melhorar a conduta humana, possibilitando, assim, salvaguardar o futuro da própria humanidade.

Assim, para o pensamento do autor, tudo se modificou, as éticas anteriores não são mais válidas, dessa forma, o destino e a providência não acompanham a evolução do homem contemporâneo. Mas, é certo que ainda permanecem algumas prescrições imediatas, tais como: a justiça e a misericórdia, ambas existindo em uma esfera próxima, como diz Hans Jonas (2006, p. 39):

[...] Mas essa esfera torna-se ensombrecida pelo crescente domínio do fazer coletivo, no qual ator, ação e efeito não são mais os mesmos da esfera próxima. Isso impõe à ética, pela enormidade de suas forças, uma nova dimensão, nunca antes sonhada, de responsabilidade.

O autor explana, detidamente, acerca das consequências do agir humano e formula um imperativo voltado para a coletividade que preconiza que não se deve agir de forma inconsequente, pois a irresponsabilidade humana poderá colocar em risco o futuro do planeta e, portanto, das próximas gerações.

Hans Jonas estabelece o seu imperativo da moralidade de modo que as ações sejam pensadas numa perspectiva coletiva, sugerindo que se "Aja de modo que os efeitos da tua ação sejam compatíveis com a permanência de uma autêntica vida humana sobre a terra"(JONAS, 2006, p.47). Este se estrutura em contraposição ao imperativo kantiano que tinha um caráter formal e que era determinado por uma máxima subjetiva do querer, algo individualizado, não levando em consideração a coletividade. Essa forma interna da vontade constitui o conteúdo do imperativo categórico. Ou segundo aconselha as palavras do próprio Kant (1999, p. 59): “Age apenas segundo uma máxima tal que possas ao mesmo tempo querer que ela se torne lei universal." Decerto, que há uma discordância entre Jonas e Kant, pois aquele tem em seu imperativo uma extensão voltada para a práxis coletiva, enquanto este é voltado para o plano individual, estando o imperativo categórico de Kant voltado ao imediato e sua consistência é a do ato consigo mesmo.

Neste sentido, Hans Jonas chama atenção para a inconsistência dos imperativos éticos tradicionais, pois estes não têm o mesmo caráter de validade diante do agir humano, que vem sendo modificado com a nova era da civilização tecnológica. Sendo assim, faz-se necessária a emergência de pensar a ética que possa garantir a existência humana, englobando também todas as formas de vida existentes na biosfera. 
Como possível ancoradouro destas questões, o autor propõe, então, o Princípio Responsabilidade, como sendo um princípio ético que pode funcionar como ponto de apoio frente ao perigo iminente que a humanidade vem sofrendo em consequência dos abusos que as novas tecnologias vêm provocando no meio em que vivemos, daí porque Hans Jonas (2006, p. 39) afirma que "A natureza como uma responsabilidade humana é seguramente um novum sobre o qual uma nova teoria ética deve ser pensada”.

Frente às características das novas tecnologias explicitadas até aqui, associadas a algo que representa potencialmente um risco para a humanidade, ainda que de forma gradual, e mesmo para o futuro do planeta, com todas as suas formas de vida, mineral, vegetal, animal, é que o autor vê a necessidade de um fundamento ontológico para se pensar a preeminência do Ser contra o não-Ser, nesse sentido, faremos uma breve incursão na metafísica que terá como objetivo "avançar além da doutrina do agir, ou seja, da ética, até a doutrina do existir, ou seja, da metafísica, na qual afinal toda ética deve estar fundada"(JONAS, 2006, p. 42).

Em concordância com o pensamento de Jonas, Nedel (2004, p. 167) expõe que "Sua ética se caracteriza por um apelo à metafísica, aos princípios de responsabilidade e de realidade". Ou seja, a preocupação com o futuro do homem é um ponto arquimediano da ética de Jonas e é por esse motivo que Hans Jonas afirma que a "responsabilidade" é o fundamento ético ideal para mensurar o agir humano, pois esse agir impensado pode colocar em risco a continuidade da vida humana sobre a Terra. Assim, "Uma ética de emergência do futuro em perigo deve ser traduzida por ações coletivas do 'Sim ao Ser' exigida do homem pela totalidade das coisas"(BARUCHELLO, 2008, p.1, tradução nossa).

Toda a preocupação do filósofo alemão em relação ao agir humano, confronta-se com as novas tecnologias e suas consequências em relação ao futuro da humanidade, pois essas mesmas tecnologias nos dias de hoje é pensada como um instrumento de poder. A partir disso surgem indagações, tais como: quais são os benefícios e malefícios que as novas tecnologias trazem a humanidade? Em meio aos avanços tecnológicos, até que ponto o ambiente será preservado? Ou ainda, a humanidade deve pagar por estas altas apostas em que as tecnologias vêm se desenvolvendo?

Como recurso metodológico para se pensar questões como as colocadas acima, que podem repercutir em um cenário catastrófico, Hans Jonas desenvolveu o que ele chamou de "heurística do temor", semelhante a um sinalizador, instrumento de consulta que exerce prioridade frente ao desejo egoísta do homem. Esse medo heurístico (refletido) poderia antever e precaver futuras calamidades que venham a ameaçar a humanidade. Como diz o próprio autor: 
"Diante das ameaças iminentes, cujos efeitos ainda podem nos atingir, freqüentemente o medo constitui o melhor substituto para a verdadeira virtude e sabedoria" (JONAS, 2006, p.65).

Mas esse medo não é um mero medo patológico, individual, e, sim, um medo consultado pelo saber, refletido e que pode ser o início para uma transformação futura, afinal, deve-se ter em mente que "a heurística do medo não seja a última palavra na procura do bem, ela é uma palavra muito útil'”(JONAS, 2006, p. 71). Portanto, quando se afirma que o mal é reconhecido de maneira mais fácil que o bem, a precaução com futuros desastres torna-se mais refletida e, consequentemente, podem-se frear acontecimentos desastrosos para a humanidade.

Em relação ao desejo do homem em dominar a natureza, o autor cita vários problemas que podem ocasionar riscos desastrosos para o futuro do planeta, e faz ainda severas críticas às utopias que apoiam os avanços tecnológicos sem apresentarem nenhum destaque para as implicações desses avanços para a natureza e seus recursos, recursos esses que estão se tornado cada vez mais escassos, por conta, dessa ilusão cega, onde o pensamento progressista versa sobre o desenvolvimento em nome do lazer, levando à população a percorrer um caminho de futuro incerto. Entre os pontos preocupantes, Hans Jonas cita alguns que dizem respeito a essa busca desenfreada pelo poder, quais sejam: a) a questão de como alimentar uma população em crescimento constante; b) a segunda questão refere-se ao fato das matérias-primas serem exploradas como fontes inesgotáveis, o que não são; c) a terceira questão diz respeito ao dispêndio de energia, considerado pelo autor como um dos problemas mais graves e que precisa de solução.

Diante de todas essas mazelas observadas na conduta humana perante o meio ambiente, a natureza vem se tornando vulnerável e os riscos de extinção se tornam manifestos, pois os pulmões da mãe-terra estão se esvaziando cada vez mais rápido. Segundo o autor, o que nubla a mente do homem é essa visão de um futuro fantasioso e artificial, de crescimento; essa exacerbação de dominação a qualquer custo comporta uma perspectiva que conduz a civilização para um futuro incerto, e é essa incerteza que preocupa Hans Jonas, pois esse ideal tende a levar ao fim da existência neste planeta.

Justamente por isso, a ética da responsabilidade tem um forte apelo para nossa época, pois está pautada em fundamentos ontológicos, mostrando-se adequada para se pensar o que se pode fazer para evitar um destino catastrófico. Sendo a exigência de seu princípio da moralidade, que é voltado para a natureza humana e para as consequências de suas ações para com a biodiversidade, um marco regulador onde a preeminência de existir contraponha-se ao do não existir. 
Hans Jonas reformula ainda a velha questão de Leibniz, onde paira a seguinte questão: por que deve existir alguma coisa ao invés do nada? Essa pergunta é fundamental na teoria jonasiana, pois na sua ética há uma obrigação incondicional da existência humana, como está expresso em seu imperativo acima citado, afinal, para autor "essa imposição se faz a partir de um dever primário com o Ser, em oposição ao nada"(JONAS, 2006, p. 87). Dessa maneira, deve existir um dever para com as gerações futuras e a categoria da responsabilidade é o fator determinante para se pensar o futuro da humanidade. Como diz Rubenstein (2009, p. 167, tradução nossa): a "Responsabilidade é semeada na estrutura do Ser".

Assim, para Jonas existe, mesmo que implicitamente, há uma passagem do Ser para o Dever, pois a humanidade não pode ser objeto de apostas e nem de um melhorismo em nome do progresso que pode, certamente, afetar o futuro das gerações vindouras em nome do presente, então, deve existir um Dever, uma obrigação para com o que está por vir, cuja preocupação é que "A existência da humanidade significa simplesmente que vivam os homens"(JONAS, 2006, p. 177).

Em seus desdobramentos reflexivos, o autor elabora alguns modelos de responsabilidade para se pensar a importância do princípio da moralidade que engloba a responsabilidade natural, parental e política. Segundo Hans Jonas, a responsabilidade natural se faz presente na relação familiar da responsabilidade parental, que é irrevogável, não pode ser interrompida, ou seja, não tira licença. Essa responsabilidade está atrelada à criança, sendo a mais elementar das responsabilidades.

Em seguida temos a responsabilidade do homem público que tem uma amplitude maior, pois sua dimensão ultrapassa as cercanias do individual e deságua na coletividade, daí a importância dos fatores sociais e políticos nessa esfera. No trecho a seguir o autor situa bem duas responsabilidades, a paterna e a política:

A esta altura, pode ser do maior interesse teórico examinar como essa responsabilidade nascida da livre escolha e aquela decorrente da menos livre das relações naturais, ou seja, a responsabilidade do homem público e a dos pais, que se situam nos extremos do espectro da responsabilidade, são as que têm mais aspectos em comum entre si e as que, em conjunto, mais nos podem ensinar a respeito da essência da responsabilidade (JONAS, 2006, p.173).

Diante desses modelos de responsabilidades, podemos afirmar o quanto o presente e o futuro devem ser preservados, pois tanto a responsabilidade paterna, mais imediata, quanto à política, fazem parte de um projeto maior capaz de garantir a existência de um futuro mais promissor para a humanidade. Ambas devem, assim, assegurar a continuidade, pois elas fundamentam as condições sine qua non para o futuro da humanidade. "Mas a responsabilidade 
por uma vida, individual ou coletiva, se ocupa antes de tudo com o futuro, bem mais do que com o presente imediato" (JONAS, 2006, p. 186).

\section{CONCLUSÃO}

As reflexões propostas pelo filósofo Hans Jonas em relação ao problema da técnica têm causado grande impacto nos meios acadêmicos, principalmente, por causa da interferência e das mudanças que surgiram a partir dos avanços da ciência, o que vem modificando o agir do homem e traz graves consequências para o meio ambiente.

Diante das implicações de toda essa problemática, o filosofo encaminhou o seu pensamento para o universo da responsabilidade moral, realizando primeiramente um regresso à metafísica com o objetivo de explicar a importância de se pensar uma ética voltada para a preeminência do Ser em relação ao nada e para o agir humano, levando em consideração um princípio fundamental que ele chamou de responsabilidade, orientado no sentido de inibir certas ações que podem levar à destruição do planeta. O recurso metodológico utilizado por Hans Jonas vai ao encontro de uma reflexão coletiva, denominado "Heurística do Medo", esse recurso visa auxiliar o homem a pensar sobre as futuras ameaças que assombram a humanidade.

E apesar de beber na fonte do saber de filosofias anteriores, no que diz respeito à ética propriamente, o autor funda um pensamento enraizado na contemporaneidade, pois, segundo ele, as éticas tradicionais não tinham um caráter emergente, estando toda a sua dimensão voltada para os limites da polis, numa perspectiva de que a natureza cuidava de si mesma, mas o progresso do homem acabou por elevar o seu poder de dominação, colocando em risco o meio em que ele vive. Por essa razão o autor insiste que a responsabilidade, juntamente com outras éticas, deve fazer parte desse cenário ora ensombrecido pelo agir humano. Pois "Isso impõe à ética, pela enormidade de suas forças, uma nova dimensão, nunca antes sonhada, de responsabilidade" (JONAS, 2006, p.39).

Dessa forma, o filósofo analisa o caráter tecnológico e reflexivo do homem, defendendo que a tecnologia aprisiona o homem, tornando-o senhor de suas vontades e consequentemente escravo das mesmas, tentado a acreditar que o progresso o impulsiona a feitos cumulativos e de grande escala. Nesse viés, o autor apresenta como premissa básica que se pense uma ética voltada para o agir coletivo, que englobe todas as formas de vida, desde as menos desenvolvidas até o topo da cadeia, pois o futuro do planeta depende da biodiversidade presente na natureza. Enfim, pode-se afirmar que Hans Jonas foi um pensador que se propôs a pensar uma ética pautada na responsabilidade humana em meios aos avanços tecnológicos e ao futuro da humanidade. 


\section{REFERÊNCIAS}

BARUCHELLO, G. Gnosis, sustainable development and racism. re-appraising Hans Jonas as a political thinker. Appraisal, Akureyri, v. 7, n. 2, p.13-20, out.2008.

JONAS, H. O Princípio responsabilidade: ensaio de uma ética para a civilização tecnológica. Rio de Janeiro: Contraponto, 2006.

KANT, I. Fundamentação da metafísica dos costumes. Lisboa: Edições 70, 1999.

NEDEL, J. Ética Aplicada: pontos e contrapontos. São Leopoldo: Unisinos, 2004.

RUBENSTEIN, A. Hans Jonas: study in biology and ethics. Springer Science, Northfield, p.160-167, fev. 2009.

RUSS, J. Pensamento ético contemporâneo. São Paulo: Paulus, 1999. 